\title{
The effects of acute oxygen changes on heart rate in the freshwater crab Poppiana dentata (Randall, 1840)
}

\author{
Delezia Shivani Singh ${ }^{1}$, Mary Alkins-Koo ${ }^{1}$, Luke Victor $\operatorname{Rostant}^{1}$ \& Azad Mohammed ${ }^{1}$ \\ ${ }^{1}$ Department of Life Sciences, Faculty of Science and Technology, Ground Floor \\ Natural Sciences Building, the University of the West Indies St. Augustine \\ Trinidad and Tobago, West Indies \\ Corresponding author: Delezia Shivani Singh (delezia_singh@yahoo.com)
}

\begin{abstract}
Heart rate is a key physiological feature that can be used to assess the response of organisms to changing environmental conditions in aquatic habitats, such as acute fluctuations in oxygen levels and hypoxic conditions. This experiment, therefore, investigated cardiac responses in a freshwater brachyuran species, Poppiana dentata, exposed to low oxygen levels. Heart rate was derived from beats per minute (bpm) signals $(\mathrm{n}=576)$ using an infrared, non-invasive technique over a $96 \mathrm{~h}$ period, under different dissolved oxygen (DO) conditions. These involved three regimes: normoxic $\left(6.8 \pm 0.1 \mathrm{mg} \mathrm{L}^{-1}\right)$, decreasing DO to hypoxic levels $(6.2$ to $\left.1.7 \mathrm{mg} \mathrm{L}^{-1}\right)$, and recovery with normoxic levels $\left(6.3 \pm 0.1 \mathrm{mg} \mathrm{L}^{-1}\right)$. Changes in heart rates among the three regimes were significant $(P<0.05)$; reflecting the shift in heart rate during different conditions of oxygen availability, normoxic (59 to $61 \mathrm{bpm}$ ), declining DO (54 to $62 \mathrm{bpm}$ ) and recovery DO (53 to $64 \mathrm{bpm}$ ). Additionally, the normal rhythmicity of heart rates under the normoxic condition was not maintained throughout most of the declining DO and recovery periods. $P$. dentata has demonstrated cardiac compensations in heart rate during low oxygen levels, providing insight into the species cardiac physiology.
\end{abstract}

Keywords: Poppiana dentata; cardiac responses; acute oxygen; freshwater crab; non-invasive; Trinidad and Tobago

Heart rate is a key physiological response in organisms that are used to assess the impacts of changing environmental conditions (Airriess \& McMahon, 1994; Bojsen et al., 1998; Burnett et al., 2013). This aspect can compensate for changes in ambient dissolved oxygen (DO) concentrations, which is not unusual since animals facing low oxygen or hypoxic environments tend to possess regulatory strategies for coping with these conditions (Burnett, 1997; Giraud-Billoud et $a l ., 2019)$. Heart rate is generally expressed as beats per minute (bpm), and it represents a useful parameter for measuring cardiac activity (Císař et al., 2018). In turn, cardiac activity is intricately linked to metabolism, with responses related to these functions reflecting the adaptations of aquatic organisms to environmental stress (Sokolova et al., 2012; Kuklina et al., 2013). Hence, heart rate may be an interesting physiological feature to explore in crustaceans, since this group may often be faced with hypoxic and other adverse environ- ments (Da Silva-Castiglioni et al., 2010; Paschke et al., 2010).

There is limited information dealing with the cardiac activity of freshwater brachyurans; most studies have focused on freshwater crayfish (McMahon et al., 1974; Wilkes \& McMahon, 1982; Villarreal, 1990; Bojsen et al., 1998; Reiber \& McMahon, 1998; Bini \& Chelazzi, 2006; Fedotov et al., 2006; Kuznetsova et al., 2010; Cooper et al., 2011; Chung et al., 2012; Udalova et al., 2012; Kuklina et al., 2014, 2018; Pautsina et al., 2014; Sladkova et al., 2016; Broughton et al., 2017; Císař et al., 2018) and marine brachyurans (Ansell, 1973; Florey \& Kriebal, 1974; McMahon et al.,1979; Hamilton \& Houlihan, 1992; Airriess \& McMahon, 1994; DeWachter \& McMahon, 1996; De Pirro et al., 1999; Frederich \& Pörtner, 2000; Paschke et al., 2010). With regards to studies involving limited oxygen as the stress factor, heart rate in both freshwater and marine decapod (crab, crayfish and lobster) species was found

Corresponding editor: Crisantema Hernández 
to generally decrease in response to declining or severely low oxygen exposures (Ansell, 1973; Spoek, 1974), with instances of bradycardia in some cases (Florey \& Kriebel, 1974; Reiber \& McMahon, 1998). However, contrasting findings were reported for some freshwater crayfish species during hypoxic exposures; no significant changes in heart rate for Orconectes rusticus (Wilkes \& McMahon, 1982) and Paranephrops zealandicus (Broughton et al., 2017), while $O$. virilis showed gradual reestablishment of pre-hypoxic rates during constant hypoxia (McMahon et al., 1974). In cases where the test organisms were subjected to a recovery period following hypoxic exposure, the heart rate gradually returned to regular or pre-test levels (Ansell, 1973; Florey \& Kriebel, 1974).

Poppiana dentata (Randall, 1840) is a freshwater crab species commonly found in low-lying freshwater habitats (Cumberlidge, 2008). P. dentata, along with Rodriguezus garmani and Microthelphusa odaelkae, is the only three valid freshwater crab species that are documented for Trinidad and Tobago. Of the three, $P$. dentata can be more frequently found in lentic, intermittent freshwater habitats. These tend to be impacted by low DO and current velocity during the dry season in Trinidad, as well as by anthropogenic activities such as agricultural runoff and residential development. Alternatively, these freshwater systems can also become rapidly flushed from adverse precipitation events that occur during the wet season. It is therefore noteworthy to understand how these factors impact on this freshwater brachyuran and its habitats, namely, how acute changes in ambient oxygen levels affect the cardiac functioning of $P$. dentata. To date, heart rate responses to oxygen stress have not been examined in freshwater crab species, neither, using a non-invasive approach. Therefore, this study sought to utilize a non-invasive technique to measure heart rate responses in $P$. dentata, during different conditions of oxygen availability; a normoxic condition of optimum DO follow by declining DO to hypoxic conditions and a recovery condition, involving a reintroduction to normoxia.

Adult, male $P$. dentata crabs $(\mathrm{n}=13)$ with carapace width (CW) 32 to $45 \mathrm{~mm}$ and weighing 21.83 to 28.23 $\mathrm{g}$ were collected from an artificial drainage system, in northwest Trinidad $\left(10^{\circ} 37^{\prime} 49.2^{\prime \prime} \mathrm{N}, 61^{\circ} 5^{\prime} 51.2^{\prime \prime} \mathrm{W}\right)$. This system empties into the Caroni River and is located in the Santa Cruz watershed of the north-western part of Trinidad. A fairly lentic freshwater habitat in character, described by a low current velocity $\left(0\right.$ to $\left.10 \mathrm{~cm} \mathrm{~s}^{-1}\right)$ and mainly mud substrates. Samples were acquired via a qualitative approach involving the deployment of 0.312 $\mathrm{mm}$ mesh sized traps. These were baited with segments of freshwater Tilapia sp. and checked daily for crabs.
The captured crabs were acclimated in captivity in $4.5 \mathrm{~L}$ aquaria for 45 days before the experiments. This lengthy acclimation period was intentionally applied to ensure that crabs in late intermoult (nearing a molt event) were not selected and, by extension, to avoid crabs undergoing molting during the experiment. Adult, male $P$. dentata crabs have been observed to have an extended intermoult period of greater than 40 days (CW: $29.74 \pm 2.65 \mathrm{~mm}$; intermoult period: $42 \pm 8$ days; work in review). The crabs were kept separately to reduce agonistic behavior and cannibalism. During acclimation, each aquarium was maintained at temperature $26^{\circ} \mathrm{C}$, a light-dark cycle of $12: 12 \mathrm{~h}$ and DO of $6.8 \pm 0.1 \mathrm{mg} \mathrm{L}^{-1}$. Crabs were fed ad lib twice a day, with commercial pellets (Kyorin Food Industries Co. Ltd.), segments of the aquatic plant, Egeria densa, (approximately $1 \mathrm{~g}$ pieces), and fragments of freshwater Tilapia sp. (0.54 to $0.71 \mathrm{~g}$ of tissue per crab). This diverse feeding regime was applied in order to accommodate an omnivorous diet. This generalist diet is typical for trichodactylid species inhabiting freshwater riverine habitats (Williner \& Collins, 2013). Each aquarium was always cleaned after feeding, along with water renewal, to ensure good water quality.

The ethical sanction was granted for performing research on this work's species (Poppiana dentata) by the Campus Ethics Committee, The University of the West Indies St. Augustine Main Campus, Trinidad and Tobago. A total of 12 crabs were selected for the experiment, based on these criteria; crabs had to be in their intermoult phase and have all their appendages intact. Heart rates were measured from these crabs using a heartbeat amplifier and logging system (2015 model), developed by Lima \& Seabra (2015), based on a non-invasive, infrared (IR) technique used to measure heart frequency or beats per minute (heart rate). The IR sensors were glued to the cardiac region of crabs using non-toxic, fixative glue. After attachment, crabs were then left to acclimatize for one week before starting the experiments. Previous trials with the same species, life stage, and monitoring conditions showed that this acclimation period was sufficient for heart rates to become regular after attachment. During the monitoring sessions, one sensor was always left open-ended (no crab attached) for the detection of possible background signals. These signals were compared with those from attached crabs and verified that the latter readings were actual beats recorded per minute, rather than from the surrounding.

Beats per minute (bpm) were simultaneously recorded for crabs in 1 min sessions, at 10 min intervals, for every hour, under three successively applied oxygen conditions. A $48 \mathrm{~h}$ normoxic treatment where crabs were exposed to optimum DO concentrations $(6.8 \pm 0.1$ 
mg L $\left.{ }^{-1}\right)$; a $24 \mathrm{~h}$ closed or declining DO treatment $(6.2$ to $1.7 \mathrm{mg} \mathrm{L}^{-1}$ ) using sealed $3.8 \mathrm{~L}$ respiratory chambers (each holding $2 \mathrm{~L}$ of water); followed by a $24 \mathrm{~h}$ recovery treatment where crabs were reintroduced to optimum (normoxic), DO concentrations. In the case of this recovery regime, crabs were transferred to chambers with stable DO levels that averaged close to normoxic, at $6.3 \pm 0.1 \mathrm{mg} \mathrm{L}^{-1}$. Crabs were allowed to settle for two hours before measurements were formally initiated for the closed and recovery treatments since the transfer of test subjects between treatments would have resulted in a disturbance. All one minute signals $(\mathrm{n}=576)$ were visually verified, processed, and then stored in order to ensure quality control of the bpm recorded, as recommended in the user guidelines (Lima \& Seabra, 2015).

Additionally, DO levels in the regimes were monitored using the ExStik ${ }^{\circledR}$ II DO meter (Extech Instruments). Adapters were installed at the top of each chamber to allow passage of the leads from the heartbeat logger and the DO meter probe. Both the normoxic and recovery periods were designed to expose the crabs to a stable level of DO. Hence, DO levels were measured at the start and end of these regimes, to ensure that the DO remained relatively constant during these periods. However, DO measurements were taken on an hourly basis for the 24 $\mathrm{h}$ closed period since the authors wanted to note the rate at which DO decreases, as well as to determine the hypoxia point within the chambers (DO levels $<2.0 \mathrm{mg}$ $\left.\mathrm{L}^{-1}\right)$. In the case of hypoxic conditions, these are generally associated with DO levels less than $2.0 \mathrm{mg} \mathrm{L}^{-1}$ (Dauer et al., 1992), so this benchmark was used to denote the onset of hypoxia for this study. DO was also measured from a control chamber (no crab), established with the same normoxic concentration and volume of dechlorinated water as those with crabs, to ensure there was no variation in DO levels resulting from the laboratory prepared water (Dalosto \& Santos, 2011). The experimental period was terminated after the recovery session, in anticipation of the crabs approaching their late intermoult phase. This latter stage would have influenced the heart rates being measured since the general activity is typically reduced in crabs approaching ecdysis (Warner, 1977).

Data exploration, involving normality checks, statistical testing, and descriptive statistics were performed using R version 3.3.1 (R Development Core Team, 2016). The alpha $(\alpha)$ level of 0.05 was utilized as the rejection criterion for the statistical tests since this is generally ideal (Dytham, 2011). The untransformed and transformed datasets for heart rates did not conform to normality after analysis with the ShapiroWilk test $(P<0.05)$ or conditions of homoscedasticity
(Levene's test $)(P<0.05)$. Therefore, the nonparametric Kruskal-Wallis test was used to explore significant differences in heart rates among the normoxic, declining DO, and recovery periods. The Wilcoxon match-paired signed-ranks test further evaluated heart rate variation for pairwise comparisons of these three regimes.

Heart rate during exposure to the normoxic condition, declining DO, and recovery over 96 hours is shown (Fig. 1). The overall median rate for the $96 \mathrm{~h}$ period was $60 \mathrm{bpm}$. However, heart rates were found to be significantly different between regimes (normoxic $v s$. declining DO: sum of positive scores $(V)$ for Wilcoxon match-paired signed-ranks test, $V=164,440$, $P<0.05$; normoxic $v s$. recovery: $V=20,237, P<0.05$; declining DO vs. recovery: $V=22,907, P<0.05)$. These differences were due to the range of heartbeats exhibited by $P$. dentata crabs exposed to different conditions of oxygen availability, such as for normoxic (59 to $61 \mathrm{bpm}$ ), declining DO (54 to $62 \mathrm{bpm}$ ) and recovery (53 to $64 \mathrm{bpm}$ ) conditions.

During the normoxic period, heart rates were fairly stable, averaging at $60 \pm 1 \mathrm{bpm}$ (mean $\pm \mathrm{SD}$, standard deviation; median: $60 \mathrm{bpm}$ ). After this treatment, the crabs were exposed to a closed treatment, in which DO levels decreased from $6.2 \mathrm{mg} \mathrm{L}^{-1}$ (start of the closed treatment) to $1.7 \mathrm{mg} \mathrm{L}^{-1}$ (end of this treatment). Heart rates during this period averaged at $58 \pm 4 \mathrm{bpm}$ (median: $61 \mathrm{bpm}$ ) and were significantly different from the rates in the normoxic period $(V=164,440, P<$ $0.05)$. A decline in median heart rate occurred during the initial $2 \mathrm{~h}$ of decreasing DO (1.4-0.5 $\left.\mathrm{mg} \mathrm{L}^{-1} \mathrm{~h}^{-1}\right)$, and this was followed by significant fluctuations within the subsequent 4 hours (Kruskal-Wallis test statistic, $H=$ 0.90 , df $=5, P<0.05$ ), when DO levels further decreased at a mean rate of $0.4 \pm 0.2 \mathrm{mg} \mathrm{L}^{-1} \mathrm{~h}^{-1}$ (unbroken circle at hour number 54 in Figure 1). Heart rates eventually re-stabilized from hour number 63 (mean \pm SD: $60 \pm 1$ bpm; median: $61 \mathrm{bpm}$ ), despite continued exposure of the crabs to hypoxic conditions $\left(0.2 \pm 0.1 \mathrm{mg} \mathrm{L}^{-1} \mathrm{~h}^{-1}\right)$. After exposure to depleting DO levels, the crabs were then reintroduced to a normoxic, steady level of DO $\left(6.8 \pm 0.1 \mathrm{mg} \mathrm{L}^{-1}\right)$, during a $24 \mathrm{~h}$ recovery period. Heart rates during recovery were also significantly different from those of the normoxic period $(V=20,237, P<0.05)$. Similar to the DO decline period, there was an initial drop in heart rates in response to the acute change in recovery DO. Irregular fluctuations also persisted throughout $16 \mathrm{~h}$ of this treatment $(56 \pm 3 \mathrm{bpm})$.

In addition to the differences noted in the bpm, the heart rate rhythmicity or diurnal pattern in heart rates also changed across different regimes. Under normoxic 


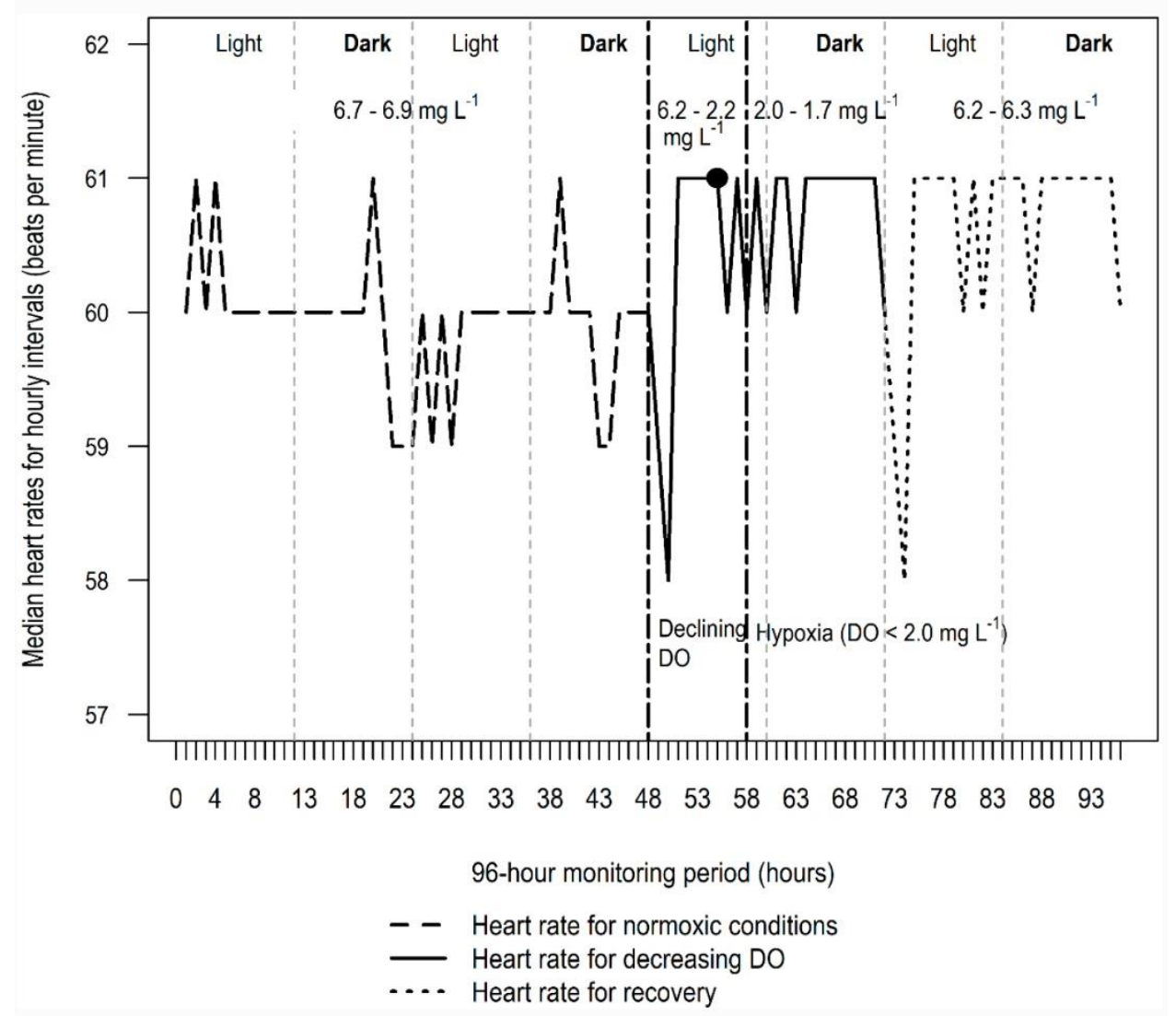

Figure 1. Median heart rates (bpm) for adult, male Poppiana dentata crabs for $96 \mathrm{~h}$. The vertical hatched lines represent the 12:12 $\mathrm{h}$ photoperiod of light and dark phases that were artificially applied over four days of monitoring. The wider, hatched vertical lines define the onset of the declining DO treatment and the hour from which DO levels declined to less than $2.0 \mathrm{mg} \mathrm{L}^{-1}$ (hypoxic conditions). The unbroken circle defined the hour from which heart rates began to fluctuate when DO levels fell below $3.0 \mathrm{mg} \mathrm{L}^{-1}$. Time at which hypoxia occurred was denoted as the hour within which the mean DO concentration fell around $2.0 \mathrm{mg} \mathrm{L}^{-1}$.

DO levels $\left(6.8 \pm 0.1 \mathrm{mg} \mathrm{L}^{-1}\right)$, heart rate followed repeating diurnal rhythmicity over two days (Fig. 1). A stable rate occurred throughout most of the light phases, with relatively heightened fluctuation being noted for the dark phases. However, this rhythmic pattern under normoxia changed when crabs experienced closed and recovery treatments (Fig. 1). A change in the diurnal pattern occurred whereby a sharp decline in heart rate was noted at the beginning of these latter periods, followed by heightened heart rate activity during the light phase and more stabilized rates observed for the dark phase. The rhythmicity of heart rates appeared to have been disrupted from exposure to hypoxic conditions, where the mean DO level reached $1.7 \pm 0.2$ mg L $\mathrm{L}^{-1}$ toward the end of the closed treatment (at the $72^{\text {nd }} \mathrm{h}$ ). This altered cardiac pattern continued during subsequent reintroduction to optimum DO (recovery) and did not revert to the original rhythmicity observed for the initial normoxic period.
Periodic changes in heart rate for $P$. dentata were observed to follow a diurnal pattern during the normoxic period, which appeared to be in sync with the $12 \mathrm{~h}$ photoperiodic shifts, similar to circadian patterns for decapod heart rate across a diurnal or $24 \mathrm{~h}$ cycle, where the cardiac activity is generally different across daytime and night (Bojsen et al., 1998; McGaw \& McMahon, 1998). Freshwater crabs tend to perform most activities related to foraging, feeding, ecdysis, and other lifestyle aspects on a nightly basis (Maitland \& Maitland, 1998; Zimmermann et al., 2009; Sant'Anna et al., 2014; personal observations), which corresponds well with $P$. dentata under normoxic, stress-free conditions since the heightened cardiac activity was associated more with the dark phase.

During the closed treatment, crabs responded to a decline in DO by stabilizing their heart rates, even throughout the hypoxic conditions. Maintaining a relatively constant heart rate during shallow oxygen 
levels highlights the flexibility and compensatory responses of the circulatory system of $P$. dentata, at least concerning extreme conditions of hypoxia. Contrary to this, is the expected deceleration in heart rates and bradycardiac instances for crustaceans exposed to low ambient oxygen (Guadagnoli et al., 2011; McGaw \& Reiber, 2015). However, P. dentata crabs responded differently by regulating heart rate, eventually maintaining relatively stable rates during low DO. A comparable response was found in the freshwater crayfish, $P$. zealandicus. No significant variation in heart rate was observed throughout a decline in oxygen pressure, despite the organisms switching from oxyregulating to oxyconforming consumption of oxygen at $6.0 \mathrm{kPa}$ (Broughton et al., 2017); it is not unexpected since invertebrates are capable of developing coping mechanisms that help them to adapt to low oxygen conditions and even rapid reoxygenation. For example, an adaptive approach known as 'Preparation for Oxidative Stress' or POS has been reported for phyla such as Arthropoda and describes an enhancement of antioxidant machinery that facilitates survival in harsh environmental conditions (Giraud-Billoud et al., 2019).

One mechanism that can facilitate cardiac regulation during hypoxic conditions is the redistribution in hemolymph fluid flow, via the cardioarterial valves (Airriess \& McMahon, 1994; Reiber \& McMahon, 1998; McGaw \& Reiber, 2015). These latter structures are under neural control and specific neurohormonal peptides (e.g., proctolin), with both stimuli being suggested to play crucial roles in cardiovascular regulation in decapods (Airiess \& McMahon, 1994; McGaw \& McMahon, 1998; Saver et al., 1998; Wilkens, 1999; McMahon, 2001; McGaw \& Reiber, 2015). Airriess \& McMahon (1994) noted cardiac adjustments for the brachyuran, Cancer magister, under hypoxic conditions, in which a redirection of hemolymph flow maintained a reliable blood supply to the scaphognathites, and by extension, continuous oxygen uptake. It is plausible that similar physiological adjustments in heart rate, and by extension circulatory flow, may have occurred in $P$. dentata during an acute decrease in available oxygen. Irregular fluctuations in bpm were noted to persist throughout recovery, and the cardiac rhythmicity of heart rates was also altered from coping with extremely low DO. During improved oxygen levels in the recovery treatment, repayment of the oxygen debt of tissues can plausibly account for the erratic heart rate and modified rhythmicity that was noted for $P$. dentata. Hypoxia can cause a shift in metabolism from aerobic to anaerobic states (DupontPrinet et al., 2013), as well as induce metabolic downregulation as part of an animal's POS induction (Giraud-Billoud et al., 2019). The latter has been reported to be associated with high antioxidant activity in anticipation of oxidative stress or elevations in ROS during reoxygenation conditions (Giraud-Billoud et al., 2019). It is plausible that the heart rate response of $P$. dentata during reoxygenation, represent an adaptive cardiac mechanism which enables the antioxidant system that deals with reoxygenation stress. Some crab species, such as Neohelice granulata and Paralomis granulosa, were reported to be POS-positive whereby high antioxidant activities (e.g., catalase (CAT) and glutathione S-transferase (GST)) were noted for various tissues, as a result of anoxic and aerial exposures (Giraud-Billoud et al., 2019). The concept of heart rate activity being associated with POS-responses to low oxygen-reoxygenation stress seems reasonable. However, this requires further validation, through investigation of specific cardiac aspects (e.g., hemolymph circulation) that facilitate antioxidant enzyme activities during ROS overproduction.

The heart rate variation observed for $P$. dentata infers compensatory responses to low DO and reoxygenation. It can be a reflection of the species survival during fluctuating DO levels within its disturbed habitats, possibly related to adaptive, physiological adjustments (Airriess \& McMahon, 1994; Paschke et al., 2010; McGaw \& Reiber, 2015) such as maintenance of a relatively stable heart rate. $P$. dentata has a local distribution involving freshwater systems that are generally prone to low DO and hypoxic conditions. These include dynamic systems such as standing pool habitats of intermittent streams (AlkinsKoo, 1990) or anthropogenically impacted watercourses. Additionally, previous physicochemical monitoring by the authors, at the site where the species was collected, revealed low DO concentrations ranging from 1.4 to $2.6 \mathrm{mg} \mathrm{L}^{-1}$. Therefore, it is conceivable for $P$. dentata to have adaptive cardiac mechanisms that correspond to survivorship in environments of fluctuating oxygen availability.

It should be noted that the responses reported for $P$. dentata in this study were determined under controlled laboratory conditions, and only for the adult size class. Seasonality, daily activities, life cycle stage, sex, and other factors related to fluctuating environmental physicochemistry, can all influence physiology. However, this study's findings can still provide vital insight into the cardiac capacity of $P$. dentata concerning acute DO changes. Also, these baseline responses can serve as benchmarks for toxicological investigations involving heart rate and other stressors, such as environmental toxicants. 


\section{ACKNOWLEDGMENTS}

This research was supported by funding from the Department of Life Sciences (Faculty of Science and Technology, The University of the West Indies St. Augustine Main Campus, Trinidad and Tobago). The authors of this study would also like to extend many thanks to Fernando Lima, Rui Seabra, and Sheeba Sreenivasan for their valuable advice and guidance, as well as Jeniece Germain, Osmond Jack and Ishwarlal Bissun for their field support. Additional gratitude is extended to the farmers of Bamboo Settlement for granting access to the sample site.

\section{REFERENCES}

Airriess, C. \& McMahon, B. 1994. Cardiovascular adaptations enhance tolerance of environmental hypoxia in the crab Cancer magister. Journal of Experimental Biology, 190(1): 23-41.

Alkins-Koo, M. 1990. The aquatic fauna of two intermittent streams in the southwestern peninsula, Trinidad. Living World Journal of the Trinidad and Tobago Field Naturalists' Club, 17: 36-42.

Ansell, A.D. 1973. Changes in oxygen consumption, heart rate and ventilation accompanying starvation in the decapod crustacean Cancer pagurus. Netherlands Journal of Sea Research, 7: 455-475.

Bini, G. \& Chelazzi, G. 2006. Acclimatable cardiac and ventilatory responses to copper in the freshwater crayfish Procambarus clarkii. Comparative Biochemistry and Physiology Part C: Toxicology and Pharmacology, 144: 235-241.

Bojsen, B.H., Witthøfft, H., Styrishave, B. \& Andersen, O. 1998. In situ studies on heart rate and locomotor activity in the freshwater crayfish, Astacus astacus (L.) in relation to natural fluctuations in temperature and light intensity. Freshwater Biology, 39(3): 455-465.

Broughton, R.J., Marsden, I.D., Hill, J.V. \& Glover, C.N. 2017. Behavioural, physiological and biochemical responses to aquatic hypoxia in the freshwater crayfish, Paranephrops zealandicus. Comparative Biochemistry and Physiology Part A: Molecular and Integrative Physiology, 212: 72-80.

Burnett, L.E. 1997. The challenge of living in hypoxic and hypercapnic aquatic environments. American Zoologist, 37(6): 633-640.

Burnett, N.P., Seabra, R., De Pirro, M., Wethey, D.S., Woodin, S.A., Helmuth, B., Zippay, M.L., Sarà, G., Monaco, C. \& Lima, F.P. 2013. An improved noninvasive method for measuring heartbeat of intertidal animals. Limnology and Oceanography: Methods, 11(2): 91-100.
Chung, Y.S., Cooper, R.M., Graff, J. \& Cooper, R.L. 2012. The acute and chronic effect of low temperature on survival, heart rate and neural function in crayfish (Procambarus clarkii) and prawn (Macrobrachium rosenbergii) species. Open Journal of Molecular and Integrative Physiology, 2: 75-86.

Císař, P., Saberioon, M., Kozak, P. \& Pautsina, A. 2018. Fully contactless system for crayfish heartbeat monitoring: undisturbed crayfish as bio-indicator. Sensors and Actuators B: Chemical, 255(1): 29-34.

Cooper, R.M., Finucane, H.S., Adami, M. \& Cooper, R.L. 2011. Heart and ventilatory measures in crayfish during copulation. Open Journal of Molecular and Integrative Physiology, 1(3): 36-42.

Cumberlidge, N. 2008. Poppiana dentata. The IUCN Red List of Threatened Species 2008. International Union for Conservation of Nature. [https://www.iucnredlist.org/species/134943/4039966]. Reviewed: January $1,2008$.

Dalosto, M. \& Santos, S. 2011. Differences in oxygen consumption and diel activity as adaptations related to microhabitat in Neotropical freshwater decapods (Crustacea). Comparative Biochemistry and Physiology Part A: Molecular and Integrative Physiology, 160(4): 461-466.

Da Silva-Castiglioni, D., Oliveira, G.T. \& Buckup, L. 2010. Metabolic responses of Parastacus defossus and Parastacus brasiliensis (Crustacea, Decapoda, Parastacidae) to hypoxia. Comparative Biochemistry and Physiology Part A: Molecular and Integrative Physiology, 156(4): 436-444.

Dauer, D.M., Rodi, A.J. \& Ranasinghe, J.A. 1992. Effects of low dissolved oxygen events on the macrobenthos of the lower Chesapeake Bay. Estuaries, 15(3): 384391.

De Pirro, M., Cannicci, S. \& Santini, G.A. 1999. Multifactorial experiment on heart rate variations in the intertidal crab Pachygrapsus marmoratus. Marine Biology, 135(2): 341-345.

DeWachter, B. \& McMahon, B.R. 1996. Haemolymph flow distribution, cardiac performance and ventilation during moderate walking activity in Cancer magister (Dana) (Decapoda, Crustacea). Journal of Experimental Biology, 199(3): 627-633.

Dupont-Prinet, A., Pillet, M., Chabot, D., Hansen, T., Tremblay, R. \& Audet, C. 2013. Northern shrimp (Pandalus borealis) oxygen consumption and metabolic enzyme activities are severely constrained by hypoxia in the Estuary and Gulf of St. Lawrence. Journal of Experimental Marine Biology and Ecology, 448: 298-307.

Dytham, C. 2011. Choosing and using statistics: a biologist's guide. Wiley-Blackwell, New Jersey. 
Fedotov, V.P., Kholodkevitch, S.V. \& Udalova, G.P. 2006. Cardiac activity of freshwater crayfish at wakefulness, rest, and "animal hypnosis." Journal of Evolutionary Biochemistry and Physiology, 42(1): 49-59.

Florey, E. \& Kriebel, M.E. 1974. The effects of temperature, anoxia, and sensory stimulation on the heart rate of unrestrained crabs. Comparative Biochemistry and Physiology Part A: Molecular and Integrative Physiology, 48(2): 285-300.

Frederich, M. \& Pörtner, H.O. 2000. Oxygen limitation of thermal tolerance defined by cardiac and ventilatory performance in spider crab, Maja squinado. American Journal of Physiology-Regulatory, Integrative and Comparative Physiology, 279(5): 1531-1538.

Giraud-Billoud, M., Rivera-Ingraham, G.A., Moreira, D.C., Burmester, T., Castro-Vazquez, A., CarvajalinoFernández, J.M., et al. 2019. Twenty years of the 'Preparation for Oxidative Stress' (POS) theory: ecophysiological advantages and molecular strategies. Comparative Biochemistry and Physiology Part A: Molecular and Integrative Physiology, 234: 36-49.

Guadagnoli, J.A., Tobita, K. \& Reiber, C.L. 2011. Changes in cardiac performance during hypoxic exposure in the grass shrimp Palaemonetes pugio. Journal of Experimental Biology, 214(23): 3906-3914.

Hamilton, N.M. \& Houlihan, D.F. 1992. Respiratory and circulatory adjustments during aquatic treadmill exercise in the european shore crab Carcinus maenas. Journal of Experimental Biology, 162(1): 37-54.

Kuklina, I., Kouba, A. \& Kozák, P. 2013. Real-time monitoring of water quality using fish and crayfish as bio-indicators: a review. Environmental Monitoring and Assessment, 185(6): 5043-5053.

Kuklina, I., Ložek, F., Císař, P., Kouba, A. \& Kozák, P. 2018. Crayfish can distinguish between natural and chemical stimuli as assessed by cardiac and locomotor reactions. Environmental Science and Pollution Research, 25(9): 8396-8403.

Kuklina, I., Sladkova, S., Kouba, A., Kholodkevich, S. \& Kozák, P. 2014. Investigation of chloramine-T impact on crayfish Astacus leptodactylus (Eschscholtz, 1823) cardiac activity. Environmental Science and Pollution Research, 21: 10262-10269.

Kuznetsova, T.V., Sladkova, G.V. \& Kholodkevich, S.V. 2010. Evaluation of functional state of crayfish Pontastacus leptodactylus in normal and toxic environments by characteristics of their cardiac activity and hemolymph biochemical parameters. Journal of Evolutionary Biochemistry and Physiology, 46: $241-250$.

Lima, F.P. \& Seabra, R. 2015. 8-Channel heartbeat amplifier and logging system. User manual, version 1.5. University of Porto, Porto, $17 \mathrm{pp}$.
Maitland, D. \& Maitland, P. 1998. Creatures of the night. Geographical, 70: 28-33.

McGaw, I.J. \& McMahon, B.R. 1998. Endogenous rhythms of haemolymph flow and cardiac performance in the crab Cancer magister. Journal of Experimental Marine Biology and Ecology, 224(1): 127-142.

McGaw, I.J. \& Reiber, C.L. 2015. The natural history of the Crustacea physiology. Cambridge University Press, New York.

McMahon, B.R. 2001. Control of cardiovascular function and its evolution in Crustacea. Journal of Experimental Biology, 204(5): 923-932.

McMahon, B.R., Burggren, W.W. \& Wilkens, J.L. 1974. Respiratory responses to long-term hypoxic stress in the crayfish Orconectes virilis. Journal of Experimental Biology, 60: 195-206.

McMahon, B.R., McDonald, D.G. \& Wood, C.M. 1979. Ventilation, oxygen uptake and haemolymph oxygen transport, following enforced exhausting activity in the dungeness crab Cancer magister. Journal of Experimental Biology, 80: 271-285.

Paschke, K., Cumillaf, J.P., Loyola, S., Gebauer, P., Urbina, M., Chimal, M.E., Pascual, C. \& Rosas, C. 2010. Effect of dissolved oxygen level on respiratory metabolism, nutritional physiology, and immune condition of southern king crab Lithodes santolla (Molina, 1782) (Decapoda, Lithodidae). Marine Biology, 157: 7-18.

Pautsina, A., Kuklina, I., Štys, D., Císař, P. \& Kozák, P. 2014. Non-invasive crayfish cardiac activity monitoring system. Limnology and Oceanography: Methods, 12(10): 670-679.

R Development Core Team. 2016. Version 3.3.1. R: a language and environment for statistical computing. $\mathrm{R}$ Foundation for Statistical Computing, Vienna, Austria. [https://www.r-project.org/]. Reviewed: June 21, 2016.

Randall, J.W. 1840. Catalogue of the Crustacea brought by Thomas Nuttall and J.K. Townsend, from the West Coast of North America and the Sandwich Islands, with descriptions of such species as are apparently new, among which are included species of different localities, previously existing in the collection of the Academy. Journal of the Academy of Natural Sciences of Philadelphia, 8(1): 106-147.

Reiber, C.L. \& McMahon, B.R. 1998. The effects of progressive hypoxia on the crustacean cardiovascular system: a comparison of the freshwater crayfish (Procambarus clarkii), and the lobster (Homarus americanus). Journal of Comparative Physiology B: Biochemical Systems and Environmental Physiology, 168(3): 168-176. 
Sant'Anna, B.S., Andrade, D.R., Watanabe, T.T. \& Hattori, G.Y. 2014. Behavioral repertoire and substrate choice of the freshwater crab Dilocarcinus pagei Stimpson, 1861 (Decapoda, Trichodactylidae). In: Ardovini, C. (Ed.). Crabs: global diversity, behavior and environmental threats. Nova Science Publishers, New York, pp. 57-73.

Saver, M.A., Wilkens, J.L. \& Airriess, C.N. 1998. Proctolin affects the activity of the cardiac ganglion, myocardium, and cardioarterial valves in Carcinus maenas hearts. Journal of Comparative Physiology B: Biochemical, Systems and Environmental Physiology, 168(7): 473-482.

Sladkova, S., Safronova, D. \& Kholodkevich, S. 2016. The study of the effect of light intensity, temperature and feeding conditions changes on the cardiac activity of crayfish-bioindicators in bioelectronic systems for surface water quality monitoring. Communications Biology, 1: 137-149.

Sokolova, I.M., Frederich, M., Bagwe, R., Lannig, G. \& Sukhotin, A.A. 2012. Energy homeostasis as an integrative tool for assessing limits of environmental stress tolerance in aquatic invertebrates. Marine Environmental Research, 79: 1-15.

Spoek, G.L. 1974. The relationship between blood haemocyanin level, oxygen uptake, and the heartbeat and scaphognathite-beat frequencies in the lobster Homarus gammarus. Netherlands Journal of Sea Research, 8(1): 1-26.

Udalova, G.P., Kholodkevich, S.V., Fedotov, V.P. \& Kornienko, E.L. 2012. Changes in heart rate and circadian cardiac rhythm as physiological biomarkers for estimation of functional state of crayfish Pontastacus leptodactylus Esch. upon acidification of the environment. Inland Water Biology, 5(1): 119-127.

Received: 5 July 2019; Accepted: 1 December 2019
Villarreal, H. 1990. Effect of temperature on oxygen consumption and heart rate of the Australian crayfish Cherax tenuimanus (Smith). Comparative Biochemistry and Physiology Part A: Molecular and Integrative Physiology, 95(1): 189-193.

Warner, G.F. 1977. The biology of crabs. Van Nostrand, New York.

Wilkens, J.L. 1999. The control of cardiac rhythmicity and of blood distribution in crustaceans. Comparative Biochemistry and Physiology Part A: Molecular and Integrative Physiology, 124(4): 531-538.

Wilkes, P.R.H. \& McMahon, B.R. 1982. Effect of maintained hypoxic exposure on the crayfish Orconectes rusticus 1. Ventilatory acid-base and cardio vascular adjustments. Journal of Experimental Biology, 98: 119-138.

Williner, V. \& Collins, P.A. 2013. Feeding ecology of the freshwater crab Trichodactylus borellianus (Decapoda: Trichodactylidae) in the floodplain of the Paraná River, southern South America. Latin American Journal of Aquatic Research, 41(4): 781792.

Zimmermann, B.L., Aued, A.W., Machado, S., Manfio, D., Scarton, L.P. \& Santos, S. 2009. Behavioral repertory of Trichodactylus panoplus (Crustacea: Trichodactylidae) under laboratory conditions. Zoologia, 26(1): 5-11. 